Original Contribution

\title{
MANAGEMENT OF DYSPNEA AND RESPIRATORY INSUFFICIENCY AS A MAIN PALLIAYIVE CARE IN MALIGNANT PLEURAL EFFUSIONS
}

\author{
D. Valchev*, Zl. Ilinov, E. Obretenov \\ Clinic of Thoracic Surgery, Prof. Dr. St. Kirkovich AD Multispeciality Hospital for Active Treatment, \\ Stara Zagora, Bulgaria
}

\begin{abstract}
OBJECTIVE: The purpose of this study is to answer the question whether the treatment of these patients leads to control of respiratory failure by relieving and eliminating dyspnea and preserving the patients' ability to care for themselves, as well as achieving reduction of the number of hospitalizations of patients with unsuccessful pleurodesis and effusion persistence.

MATHERIAL AND METHODS: 165 patients with malignant pleural effusions were treated in the Clinic of Thoracic Surgery for the period 01 January 2013 - 31 May 2016. 70 patients underwent surgeries with single-port VATS, 66 patients were operated on with conventional VATS, while 29 patients were treated with thoracocentesis and drainage.

RESULTS: Of all 165 alone 5 patients, constituting $3.03 \%$ of the total number of patients, had to be admitted to the hospital for a second time due to reaccumulation of pleural effusion within the next 30 days. Satisfactory dyspnea control was established, allowing the patients to take care of themselves.

CONCLUSION: The surgical procedures - single-port and conventional VATS surgeries, thoracocentesis, drainage and placement of long-term pleural catheter with, or without, pleurodesis constitute part of the procedures achieving control over dyspnea in patients with MPE.
\end{abstract}

Key words: Management, MPE - malignant pleural effusion, dyspnea

\section{INTRODUCTION}

Dyspnea management providing control over the accumulation of pleural fluid is part of the palliative procedures complex and is included in the whole management of MPE. $(1,2)$ Treatment goals for these patients should focus on the relief or elimination of dyspnea, restoration and preservation of the patients' ability to care for themselves and be physically active, minimization or elimination of hospitalizations, as well efficient use of palliative care. $(1,3,4)$ Besides managing the process of the primary disease with chemotherapy, surgery or radiation therapy, the main concern in patients with MPE is the palliative treatment of dyspnea. (1) The issues referring to the MPE palliative treatment shall be discussed in greater detail in the present study. Dyspnea palliative treatment in patients with MPE is managed by the process of removing the effusion from the pleural membrane area through the least invasive

\footnotetext{
*Correspondence to: Valchev D., Clinic of Thoracic Surgery, Prof. Dr. St. Kirkovich AD Multispeciality Hospital for Active TreatmentStara Zagora, Bulgaria; e-mail: dg_valchev@abv.bg
}

procedure for the longest possible period within the patient's limited survival period. (1, 2) The European Respiratory Society (ERS) and the American Thoracic Society (ATS) recommend to drain no more than $1500 \mathrm{ml}$ of fluid in a single procedure and to terminate aspiration at the first signs of rapid lung expansion (dyspnea, chest pain, persistent cough). Aspiration may be repeated at twohour intervals till the said symptoms - dyspnea, chest pain, persistent cough are manifested again. (3) The methods for removing the fluid from the pleural cavity include single drainage procedure, thoracentesis with pleural catheter placement / thoracostomy catheter/ or videoassisted thoracoscopic surgery (VATS). The pleural catheter placement and the VATS procedure can be followed by pleurodesis. (1, 5) The scope of the treatment conducted depends mainly on two factors, i.e. the severity of the symptoms caused by MPE and the patient's performance status.

\section{Catheter Thoracostomy}

It is the placement of an intercostals catheter in the pleural cavity (blindly or following an echographic of computed tomography image guidance) for a continuous pleural drainage 
VALCHEV D., et al.

with a Heimlich valve. Catheter thoracostomy may be preceded by VATS with operative visualization of the pleural cavity and pleural biopsy for diagnosis purposes. However VATS can only be used for patients who can safely tolerate anesthesia and one-lung selective ventilation. Both the large-caliber catheter (28$36 \mathrm{~F}$ ) and the small-caliber one (7-16 F) may be used for a reliable drainage procedure, the results being equivalent in both cases. $(3,4,6$, 7) Our experience shows that smaller-bore catheters /14 Charier caliber/ are better tolerated by patients /they are easier to use, cause minimum intercostals pain and are not felt as foreign bodies/, they more rarely cause complications and are more reliable as a whole. In our opinion catheters smaller than 14 Charier caliber are more easily damaged because of bending or blockage with protein conglomerates and fibrin, especially when their periods of use exceed 1-2 months. The thoracostomy catheter should not be kept for a prolonged period of time because of the risk of infection, empyema, pneumothorax, etc. Reaccumulation of MPE is observed in about $80 \%$ of the patients within 30 days after the catheter removal. $(1,3)$ Therefore, the method is therapeutic enough for patients with short expected post-operative survival of 1-3 months. (1) Patients with longer survival should undergo an alternative procedure for reaccumulation control.

Thoracenthesis is usually performed at the bedside, observing all aseptic and antiseptic rules. It is done in the fifth intercostals space, anterior to midaxillary line in the triangle of safety. Separated MPE most frequently cannot be drained by a single drainage and a second catheter has to be placed, which, often and almost obligatory, is done after CT image guidance or under echographic control.

Pleurodesis agents

Although talc powder is considered to be the most effective pleurodesant, there is enough evidence that incidence of ARDS following talc pleurodesis can be as high as $9.1 \%$ of cases as a result of intense pleuritis. (8) The studies published show contradictory results as regards the talc deposition in the lung alveoli with subsequent ARDS. (8, 9) Scientific literature supports the opinion that complications may be explained with the application of big doses of talc, although no reliable evidence can be furnished for that. Some authors think that the difference in complications following talc pleurodesis can be explained with the size of talc particles used in different studies. (8)
A prospective randomized study was conducted with the object of comparing the efficacy, safety and outcome of thoracoscopic talc poudrage (TTP) as compared to povidoneiodine pleurodesis (PIP) through thoracostomy tube as a palliative preventive treatment of MPE /malignant pleural effusion/ as a result of metastatic breast cancer. (10) A total of 42 patients were enrolled in the prospective trial (22 of them received talc poudrage and 20 patients received povidone-iodine pleurodesis through a pleural catheter in a procedure performed at the bedside). There were no inhospital deaths. TTP caused severe pleuritic chest pain ( $18 \%$ versus $0 \%, \mathrm{P}=0.2)$, fever $(18 \%$ versus 5\%) and longer hospital stay $(\mathrm{P}=0.009)$. Both groups achieved good symptomatic relief. A recurrence of MPE requiring intervention is insignificant in both groups (2 versus 3 patients, $\mathrm{P}=\mathrm{NS})$. Despite the comparatively small number of patients included in the study it can be concluded that povidone-iodine is easily available, cost effective and safe and can be administered through a pleural drainage and repeated if necessary. Povidone iodine is a good alternative to TTP. (10) A similar study was conducted to compare the efficacy, safety and results of thoracoscopic talc powder (TTP) to talc-suspension pleurodesis by cataract thoracostomy as palliative treatment of MPI /malignant pleural effusion/, which unequivocally proves the advantage of talcpowdered pleurodesis. $(11,12,13)$

Measures taken in case of Pleurodesis insufficiency

Pleurodesis failure may occur as a result of incorrect pleurodesis techniques or bad selection of patients (for example patients with trapped lung or main bronchus occlusion). Recurrency after talc pleurodesis is not common, but we do sometimes have such cases. When the first pleurodesis for malignant pleural effusion fails, a number of alternatives can be applied. The pleurodesis can be repeated by instillation of /most frequently talc slurry or povidone-iodine, a sclerotic agent through a catheter in the pleural cavity or through thoracoscopy or talc poudrage. $(9,10)$ The placement of an indwelling pleural catheter /thoracostomic catheter/ is the procedure of choice in patients with short expected survival /advanced cancer intoxication and/or generalized oncological disease/. Pigtail catheters can also be suitable for patients with a severe clinical condition.

\section{MATERIAL AND METHODS}

165 patients with malignant pleural effusions were treated in the Clinic of Thoracic Surgery for the period 01 January 2013-31 May 2016. 
70 patients underwent surgeries with singleport VATS, 66 patients were operated on with conventional VATS, while 29 patients were treated with thoracentesis and drainage. The total number of patients included in the study is 165. These are procedures significantly improving the quality of remaining life in patients with malignant pleural effusion.

We have adopted the following practice in our work:

1. During VATS, single-port or conventional, having done the diagnostic assessment activities, the lung liberalization and the evacuation of the liquid contents, we check the possibility for lung reexpansion. Should the findings be positive, we perform talc poudrage. If the findings are negative - no possibility of lung reexpansion /trapped lung, adhesions that do not allow even parenchyma expansion/ we do not perform pleurosesis and leave the indwelling pleural catheter.

2. If there are contraindications for conducting general selective ventilation /bad performance status, severe concomitant diseases, patient's refusal to undergo general anesthesia/ we perform VATS, single-port or conventional, under local modified anesthesia, limiting our activities to exploration, effusion evacuation, diagnostic assessment /biopsy/, trapped lung assessment and if there are any indications, we perform talc slurry pleurodesis.

3. If there are contraindications for conducting general selective ventilation /bad performance status, severe concomitant diseases, patient's refusal to undergo general anesthesia and expected survival under 2 months/ we conduct thoracentesis and place a pleural catheter. Having drained the whole quantity of pleural fluid and reduced the pleural discharge under $150 \mathrm{ml} / 24$ hours, we conduct povidone-iodine pleurodesis.
VALCHEV D., et al.

4. In both cases the catheter is removed after the secretion is reduced to less than 50 $\mathrm{ml} / 24$ hours.

In our experience the instilling of about 4 grams of talc powder with particle size $>15 \mu \mathrm{m}$ is the most efficient procedure if it is spread evenly on both pleural sheets/due to the present pleural secretion in the hours to follow the talc powder is diluted in the secretion and is more evenly spread/.

Video-assisted thoracoscopic surgery for talc pleurodesis

Talc poudrage is done through video-assisted thoracoscopic surgery VATS under general intubation anesthesia with a double-lumen endotracheal tube and one-lung selective ventilation. All residual fluid is aspirated, the loculations /adhesions/, if any, are divided. Pleural biopsies are performed if the process is not histologically confirmed before the procedure. Before deciding on pleurodesis it is obligatory to confirm the fact that lung reexpansion is possible. Powder sprayer is used to evenly spread 4-6 g of talc over the pleural surface. The drainage is removed when the lung is filly expanded and the fluid output drops to $50 \mathrm{ml} / 24$ hours. If that result cannot be obtained for a number of days, the patient will be discharged with the catheter in place for outpatient management. Chest X-ray tests are performed in the first and second weeks. Should pleurodesis be achieved the pleural catheter is removed, usually within 2 weeks after the procedure.

\section{RESULTS}

165 patients with malignant pleural effusions were treated in the Clinic of Thoracic Surgery for the period 01 January 2013-31 May 2016. $70(42.42 \%)$ patients underwent surgeries with single-port VATS, $66(40 \%)$ patients were operated on with conventional VATS, while $29(17.58 \%)$ patients were treated with thoracentesis and drainage. The total number of patients included in the study is 165 . (Figure 1)

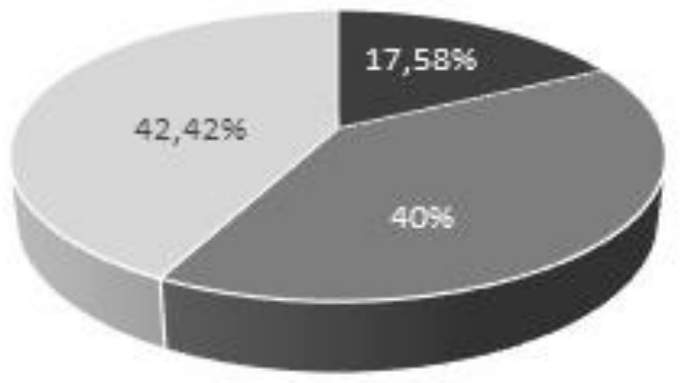

- Thor acentesis - Conventional VATS - Single-port VATS Total number of patiens 165

Figure 1. Total number of patients

Trakia Journal of Sciences, Vol. 15, № 3, 2017 
Lethal exitus during the hospitalization period occurred in 6 patients, the mortality rate amounting to $3.63 \%$. Two of the patients were operated on with single-port VATS, two of them underwent surgeries with conventional VATS, while the other two patients were treated with thoracentesis and drainage. The lethal exitus occurred within the $9^{\text {th }}$ postoperative day, the average period being 3.6 days. The main reasons for the patients' deaths
VALCHEV D., et al. were chronic acute respiratory failure and acute heart failure.

\section{Postoperative survival.}

The average postoperative survival is distributed as follows: Conventional VATS procedure -6.75 months, 9 days to 24 months range; Single-port VATS procedure -6.56 months, 3 days to 52 months range; Thoracentesis and drainage- 2 months, 3 days to 7 months range. (Figure 2)

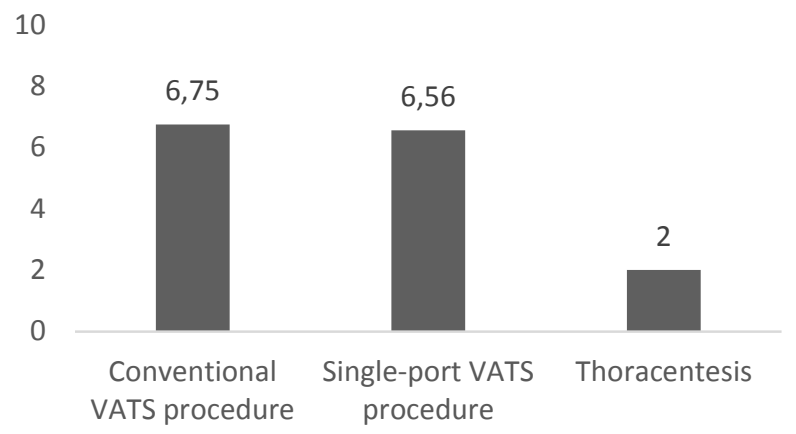

Figure 2. Average postoperative survival in months.

Trapped lung and partially unfolded lung with unsuccessful reexpansion necessitated the placement of long-term catheter and Heimlich valve to 43 patients. 13 of 29 patients had thoracentesis, 17 of 70 patients underwent single-port VATS surgery, while 10 of 66 patients were operated on with conventional VATS surgery. Heimlich valve was placed to 3 of the patients due to trapped lung. As a result a long-term reexpansion of the lung parenchyma was achieved and no pleural fluid was accumulated for a period exceeding 3 months. In 5 patients representing $3.03 \%$ of the total, should be hospitalized again due to fluid re-accumulation over the next 30 days. (Figure 3)

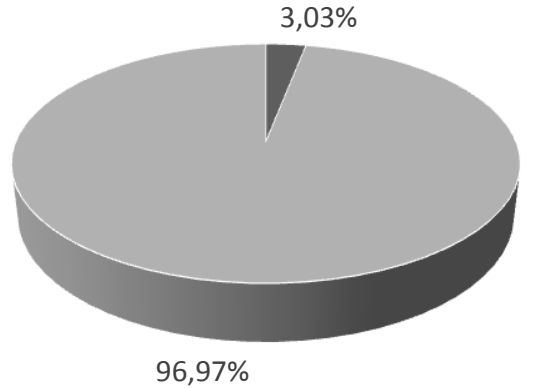

Figure 3. Total number of patient 165. Lasting pleurodesis $-96,97 \%$; Reaccumulation of fluid $-3,03 \%$.

Dyspnea and respiratory failure were under sufficient control and the patients were able to care for themselves. Minimum complications like bleeding and port site implantation metastases were observed during that period. In our study we have documented one case of a patient in the sixth postoperative month /implantation metastasis of adenocarcinoma in the chest wall muscles which had been successfully excised/ with postoperative pain with intercostals neuritis, postoperative empyema, etc. The results of this series of 165 patients, are commensurate with the results of most authors working on this theme.

\section{DISCUSSION}

Malignant pleural effusion is common in the advanced stages of malignant diseases. There are different methods for palliative management of dyspnea in these patients. A careful assessment of the expected survival and the quality of remaining life is needed when deciding between thoracenthesis with long-term placement of a pleural catheter or additional pleurodesis. The assessment is important because of the limited survival period of patients and the mixed effect over the functional respiratory characteristics. It must be borne in mind that the survival of these patients usually varies within 3-12 months. $(1,4)$ These are palliative surgical procedures allowing a comparatively decent remaining life of patients with advanced malignant pleural effusions, relieving them of the torturing dyspnea symptoms and, at the same time, relieving the thoracic surgeon of the necessity to constantly evacuate the effusion. For 
patients with expected survival period exceeding 3 months pleurodesis should be considered an appropriate procedure. Talc is the most efficient, cost-effective and available pleurodesis agent. For patients who can tolerate general anesthesia with a doublelumen endotracheal tube and lung ventilation VATS procedure is the number one choice in the diagnosis and treatment algorithm including effusion drainage, removal of lung adhesions and, if necessary, talc poudrage pleurodesis. $(9,12,13,14)$ For patients who cannot tolerate one-lung selective ventilation, but the assessment indicates possible lung reexpansion after the effusion evacuation, the procedure of choice must be the insertion of a thoracostomic catheter for effusion drainage, the fluid discharge reaching less than 100 $\mathrm{ml} / 24$ hours, followed by talc slurry pleurodesis, or povidone-iodine pleurodesis, which can achieve similar results with talc poudrage applied after VATS. $(11,12,13)$ The most difficult questionto answer is whether patients' survival is increased after pleurodesis. Pleurodesis is purely a palliative procedure which reduces mortality from respiratory compromise thus improving life quality and long-term survival. A great number of clinical factors have been used as prognostic factors for assessment of survival after pleurodesis, including the organ of origin of malignancy, malignancy, cell type (adenocarcinoma, squamous cell carcinoma, small-cell carcinoma, etc.), tumour stage, pleural fluid characteristics, and performance level. Unfortunately, despite the careful selection $32 \%$ of the patients do not survive 30 days after the pleurodesis. (10) Regarding the MPE management the American Thoracic Society and the European Respiratory Society recommend that pleurodesis must be used only with patients whose pleural fluid $\mathrm{pH}$ values exceed 7.30, because there exist a direct correlation between the low $\mathrm{pH}$ level and poor short-term survival. $(15,16)$ Patient's performance status is the most important criterion for assessing the duration of survival after pleurodesis. (17) Single VATS access is recommended as the most safe and successful in the diagnosis and treatment of malignant pleural effusion. (18)

\section{CONCLUSION}

Finally, we confirm that the surgical procedures - single-port and conventional VATS surgeries, thoracocentesis, drainage and placement of long-term pleural catheter with, or without, pleurodesis constitute part of the procedures to achieve effective control of dyspnea in patients with MPE.

\section{REFERENCES}

1. DK Muduly, SVS Deo, TS Subi, AA Kallianpur, and NK Shukla. An Update in the Management of Malignant Pleural Effusion; Indian J Palliat Care. May-Aug; 17(2): 98-103, 2011.

2. Neragi-Miandoab S. Malignant pleural effusion, current and evolving approaches for its diagnosis and management. Lung Cancer.;54:1-9, 2006.

3. Konstantinos Zarogoulidis, Paul Zarogoulidis, Kaid Darwiche, Kosmas Tsakiridis, Nikolaos Machairiotis, Ioanna Kougioumtzi, Nikolaos Courcoutsakis, Eirini Terzi, Bojan Zaric, Haidong Huang, Lutz Freitag, and Dionysios Spyratos: Malignant pleural effusion and algorithm management; J Thorac Dis. Sep; 5(Suppl 4): S413-S419, 2013.

4. Antunes G, Neville E. Management of malignant pleural effusions. Thorax:;55:981-3, 2000.

5. Juan Chen, Zhu Li, Ning Xu, Xin Zhang, $\mathrm{Yu}$ Wang, and Dianjie Lin; Efficacy of medical thoracoscopic talc pleurodesis in malignant pleural effusion caused by different types of tumors and different pathological classifications of lung cancer; Int J Clin Exp Med.; 8(10): 18945-18953, 2015.

6. Sahin U, Unlu M, Akkaya A, Ornek Z. The value of small-bore catheter thoracostomy in the treatment of malignant pleural effusions. Respiration:;68:501-5, 2001.

7. Parulekar W, Di Primio G, Matzinger F, Dennie C, Bociek G. Use of small-bore vs large-bore chest tubes for treatment of malignant pleural effusions. Chest.;120:19252001.

8. Janssen JP, Collier G, Astoul P, Tassi GF, Noppen M, Rodriguez-Panadero F, et al. Safety of pleurodesis with talc poudrage in malignant pleural effusion: A prospective cohort study. Lancet.;369:1535-9, 2007.

9. Huan Xia, Xiao-Juan Wang, Qiong Zhou, Huan-Zhong Shi, Zhao-Hui Tong; Efficacy and Safety of Talc Pleurodesis for Malignant Pleural Effusion: A MetaAnalysis; Journal List PLoS One.; 9(1): e87060, 2014.

10.Mohsen TA, Zeid AA, Meshref M, Tawfeek N, Redmond K, Ananiadou OG, et al. Local iodine pleurodesis versus thoracoscopic talc insufflation in recurrent malignant pleural effusion: A prospective randomized control trial. Eur $J$ Cardiothorac Surg.;40:282-6, 2011.

11.Stefani A, Natali P, Casali C, Morandi U. Talc poudrage versus talc slurry in the treatment of malignant pleural effusion. A 
VALCHEV D., et al.

prospective comparative study. Eur $J$ Cardiothorac Surg.;30:827-32, 2006.

12.Dresler CM, Olak J, Herndon JE, 2nd, Richards WG, Scalzetti E, Fleishman SB, et al. Phase III intergroup study of talc poudrage vs talc slurry sclerosis for malignant pleural effusion. Chest.;127:90915, 2005.

13. Stefani A, Natali P, Casali C, Morandi U. Talc poudrage versus talc slurry in the treatment of malignant pleural effusion. A prospective comparative study. Eur J Cardiothorac Surg.;30:827-32, 2006.

14. Schulze M, Boehle AS, Kurdow R, Dohrmann P, Henne-Bruns D. Department of General and Thoracic Surgery, ChristianAlbrechts-University Hospital, Kiel, Germany.; Effective treatment of malignant pleural effusion by minimal invasive thoracic surgery: thoracoscopic talc pleurodesis and pleuroperitoneal shunts in
101 patients.; The Annals of thoracic surgery. 06 27, 2001.

15.Heffner JE, Heffner JN, Brown LK. Multilevel and continuous pleural fluid $\mathrm{pH}$ likelihood ratios for evaluating malignant pleural effusions. Chest.;123:1887-94, 2003.

16.Heffner JE, Nietert PJ, Barbieri C. Pleural fluid $\mathrm{pH}$ as a predictor of survival for patients with malignant pleural effusions. Chest.;117:79-86, 2000.

17. Burrows CM, Mathews WC, Colt HG. Predicting survival in patients with recurrent symptomatic malignant pleural effusions: An assessment of the prognostic values of physiologic, morphologic, and quality of life measures of extent of disease. Chest.;117:73-8, 2000.

18.Alar T, Ozcelik C.; Single-incision thoracoscopic surgery of pleural effusions for diagnosis and treatment. Surg Endosc. Nov;27(11):4333-6, 2013. 